\title{
A COMPARATIVE STUDY OF THE DIFFERENT DOSES OF MAGNESIUM SULPHATE AND FENTANYL AS ADJUVANTS TO BUPIVACAINE [0.5\% HEAVY] FOR LOWER ABDOMINAL SURGERIES UNDER SUBARACHNOID BLOCK
}

\author{
Syed Ali Aasim ${ }^{1}$, Srikanth Reddy², Maheshwar Reddy ${ }^{3}$, K. Anil Kumar $^{4}$, Vishnu ${ }^{5}$, Sanjeev Rao ${ }^{6}$, Shakeeb Mohammed ${ }^{7}$ \\ 1 Professor \& HOD, Department of Anaesthesiology, Chalmeda Anand Rao Institute of Medical Sciences, Karimnagar. \\ ${ }^{2}$ Associate Professor, Department of Anaesthesiology, Chalmeda Anand Rao Institute of Medical Sciences, Karimnagar. \\ ${ }^{3}$ Assistant Professor, Department of Anaesthesiology, Chalmeda Anand Rao Institute of Medical Sciences, Karimnagar. \\ ${ }^{4}$ Assistant Professor, Department of Anaesthesiology, Chalmeda Anand Rao Institute of Medical Sciences, Karimnagar. \\ ${ }_{5}^{5}$ Assistant Professor, Department of Anaesthesiology, Chalmeda Anand Rao Institute of Medical Sciences, Karimnagar. \\ ${ }^{6}$ Assistant Professor, Department of Anaesthesiology, Chalmeda Anand Rao Institute of Medical Sciences, Karimnagar. \\ ${ }^{7}$ Final Year, Post Graduate Student, Department of Anaesthesiology, Chalmeda Anand Rao Institute of Medical Sciences, Karimnagar.
}

\section{ABSTRACT}

\section{BACKGROUND}

Spinal anaesthesia is the most commonly used technique for infraumbilical surgeries and it has some disadvantages, such as a short duration of motor blockade and post-operative analgesia. This study was designed to evaluate the effects of additive agents of fentanyl and magnesium sulphate along with Bupivacaine for prolongation of analgesia and motor blockade during spinal anaesthesia for infraumbilical surgeries.

\section{METHODS}

This study was conducted in 60 patients of both sexes of ASA physical status I and II scheduled for infraumbilical surgeries. Patients were randomly divided into two groups and were given the drugs intrathecally as per group distribution; Group BFbupivacaine $15 \mathrm{mg}(0.5 \%$ heavy) with fentanyl $25 \mu \mathrm{g}$, Group BM-bupivacaine $15 \mathrm{mg}$ (0.5\% heavy) with magnesium $100 \mathrm{mg}$ intrathecal.

\section{RESULTS}

There was a similar increase in duration of analgesia in Group BF (378.21 min.) as compared to Group BM (331.12 min.). In Group (BF), all haemodynamic parameters are decreased by more than $19 \%$. There was an increase in duration of motor blockade more in Group (BF) compared to Group (BM).

\section{CONCLUSION}

In conclusion, $(100 \mathrm{mg})$ magnesium sulphate or $(25 \mu \mathrm{g})$ fentanyl as adjuvants with bupivacaine to spinal anaesthesia. Both drugs are significantly prolonging the duration of both sensory block and analgesia, but magnesium sulphate provides better haemodynamic stability than fentanyl.

\section{KEYWORDS}

Bupivacaine (0.5\%), Magnesium Sulphate, Fentanyl, Spinal Anaesthesia, Lower Abdominal Surgeries.

HOW TO CITE THIS ARTICLE: Aasim SA, Reddy S, Reddy M, et al. A comparative study of the different doses of magnesium sulphate and fentanyl as adjuvants to bupivacaine [0.5\% heavy] for lower abdominal surgeries under subarachnoid block. J. Evolution Med. Dent. Sci. 2016;5(32):1735-1738, DOI: 10.14260/jemds/2016/409

\section{INTRODUCTION}

Spinal anaesthesia is the most commonly used technique for infraumbilical surgeries, as it is cost effective and easy to administer. However, postoperative pain control is a major problem, because spinal anaesthesia using only local anaesthetics is associated with relatively short duration of action and thus early rescue analgesic is needed in the postoperative period. Various drugs such as clonidine, midazolam, fentanyl and others have been studied to prolonging the effect of spinal anaesthesia.

Financial or Other, Competing Interest: None.

Submission 04-03-2016, Peer Review 31-03-2016,

Acceptance 05-04-2016, Published 21-04-2016.

Corresponding Author:

Dr. Syed Ali Aasim,

Department of Anaesthesiology

(CAIMS), Bommakal Dist.

Karimnagar-505001,

Telangana State.

E-mail: aasim.dr@rediffmail.com

DOI: $10.14260 /$ jemds/2016/409
1) Fentanyl is highly lipid soluble and diffuses into the spinal cord and it binds with dorsal horn receptors rapidly when administered intrathecally. This produces a rapid onset of analgesia and with minimal cephalic spread.

2) Magnesium sulphate blocks the calcium influx and non-competitively antagonises (NMDA) N-methyl-Daspartate receptor channels and that limitations to parenteral route of magnesium for modulation of antinociception via NMDA channel antagonism include insufficient blood brain penetration to achieve effective Cerebrospinal Fluid (CSF) concentrations. (1),(2)

Hence, in our study, intrathecal magnesium potentiates duration of analgesia like fentanyl and also avoids the side effects posed by intrathecal fentanyl. We compared two different doses of intrathecal magnesium and fentanyl as spinal adjuvants for lower abdominal surgeries.

\section{MATERIALS AND METHODS}

This study was conducted following Ethical Committee of the Institution, a total of 60 patients scheduled for elective surgeries of the lower abdominal were selected for the study 
and randomly allocated into two groups. Patients of both sexes of American Society of Anaesthesiologists (Physical status Grade I and Grade II), between the ages of 18-60 years with surgery below the level of the umbilicus were included in this study. Anticipated duration of the surgery is $<180 \mathrm{~min}$. Patients with cardiovascular diseases and hepatorenal and contraindications to regional anaesthesia such as local infection, bleeding disorders, patients who had received magnesium sulphate and opioid agonist/antagonist by other route and those patients' allergy to opioids also excluded from this study.

Thorough pre-anaesthetic check-up and including all routine investigations were done. Alprazolam $0.25 \mathrm{mg}$ were given as pre-medication 12 hours before planned surgery, inj. ranitidine $50 \mathrm{mg}$, inj. ondansetron $4 \mathrm{mg}$ given $30 \mathrm{~min}$. before planned surgery. The procedure was clearly explained to the patient and written informed consent was taken. After shifting the patient to operation theatre, we checked baseline values of the Heart Rate (HR), Systolic Blood Pressure (SBP), Diastolic Blood Pressure (DBP) and Electrocardiogram and oxygen saturation were recorded. After securing Intravenous (IV) line access, all patients received an IV preload of (10 $\mathrm{mL} / \mathrm{kg}$ ) Ringer's lactate solution before giving spinal anaesthesia. With under aseptic precautions, a 25-gauge Quincke needle was inserted intrathecally via the (L3-L4/L4L5) interspace by midline approach of the patient in sitting position. After confirmation of CSF, anaesthetic solution given intrathecally. No additional analgesia was administered unless patient complained of pain.

Blinding was achieved through the use of equal amount of drugs (3.5 mL), while syringes used were labelled as (BF) and (BM) according to their content. Identical coded syringes prepared by persons not involved in the study were randomly handed over to the anaesthetists, who were unaware of the identities of the drug. Randomisation was done using closed envelope method. Two groups were labelled as follows: Group (BF) - 15 mg bupivacaine (Heavy) with $25 \mu \mathrm{g}$ fentanyl, Group (BM) - $15 \mathrm{mg}$ bupivacaine (Heavy) with $100 \mathrm{mg}$ magnesium (total volume - $3.5 \mathrm{~mL}$ ), magnesium was taken in insulin syringe in both groups as per requirement. Patients in whom more than two attempts and an approach other than midline was used were excluded from the study. Patients were placed in supine position once the drug was administered. No tilt of the table was allowed till 20 min. after the administration of the drug, at which time the level of the blockade was noted as the "Highest level of block achieved" (Sensory level).

Sensations were tested by pinprick method with 23gauge needle and the quality of motor block was assessed using Bromage score, which was measured till $20 \mathrm{~min}$. of subarachnoid block after which surgery was started. Visual analogue pain scale (VAS) scores were explained to the patient pre-operatively and were recorded before the intrathecal injection and post-operatively up to $24 \mathrm{~h}$. Rescue analgesia was given when VAS score was $>3$. Pruritus and somnolence were assessed before the intrathecal injection and at 5, 10, 15 and $30 \mathrm{~min}$. intervals till the end of the surgery. Duration of analgesia was recorded as the time from intrathecal injection to the time of first complaint of pain, first request for analgesia or a reported VAS $>3$.

The onset of motor blockade was assessed at $5 \mathrm{~min}$. interval till 20 min. (M5, M10, M15 and M20). Somnolence was assessed as per sedation scale: 1=fully awake, $2=$ somnolent and responds to call, $3=$ somnolent and responds to verbal stimulation and $4=$ asleep and responds to only painful stimulation.

Systolic and diastolic blood pressures were recorded 5 min. before (i.e. baseline parameters) and every $5 \mathrm{~min}$. for the first 20 min. after the administration of subarachnoid block and thereafter every $5 \mathrm{~min}$. till the end of the surgery. Systolic blood pressure $20 \%$ below the baseline or $<90 \mathrm{mmHg}$ was treated with IV bolus of lactated Ringer's solution or ephedrine $6 \mathrm{mg}$ if required. Duration of analgesia was recorded as the time from intrathecal injection to the time of first complaint of pain, first request for analgesia or VAS $>3$. Rescue analgesia consisted of injection tramadol $50 \mathrm{mg}$ IV. Sample size was calculated using statistical software Epi Info 2000 (CDC Atlanta, USA). Considering the significant level of probability at $5 \%(\mathrm{P}<0.05)$ and assuming $35 \%$ difference in the duration of analgesia with intrathecal magnesium (100 $\mathrm{mg}$ ) or intrathecal fentanyl as being clinically important, we calculated that 30 patients would be required in each group to achieve $80 \%$ power at the $5 \%$ significance level to detect a true difference among the two groups.

The data were analysed using SPSS version 20 and all means are expressed as mean \pm standard deviation (SD). The comparisons among the groups were done using ANOVA followed by Bonferroni test for multiple comparisons. Appropriate univariate and bivariate analysis were carried out using the Student's t-test for the continuous variable (Age) and two-tailed Fisher exact test or Chi-square test for categorical variables. The critical levels of significance of the results were considered at 0.05 levels, that is $\mathrm{P}<0.05$ was considered as statistically significant.

\section{RESULTS}

A 60 number of patients were included in the study with 30 in each group. Demographic parameters were comparable in all the groups. All the patients in Group (BM) achieved the same score in 15 min. In Group (BF), Bromage score 3 was achieved by all the patients in $20 \mathrm{~min}$. In Group (BF), all the haemodynamic parameters (HR, SBP, DBP) decreased by more than $20 \%$ when compared to baseline parameters.

In the other Groups (BM), changes in all the parameters were within the clinically acceptable range of $\pm 20 \%$ from baseline.

One patient in Group (BF) had sensory blockade below T10, whereas 9 and 8 patients respectively in Groups (BM) block below $\mathrm{T} 10$.

Rescue analgesia was administered when VAS score was $>3$; 10 patients needed rescue analgesia in Group (BF), 11 in Group (BM).

Comparison of Mean Duration of Analgesia and Complete Recovery and Rescue Analgesia Requirement in Two Groups

\begin{tabular}{|c|c|c|c|}
\hline $\begin{array}{c}\text { Group } \\
\text { GROUP }\end{array}$ & $\begin{array}{c}\text { Duration } \\
\text { of } \\
\text { BF }\end{array}$ & $\begin{array}{c}\text { Complete } \\
\text { Analgesia } \\
\text { Recovery } \\
\text { (Min.) }\end{array}$ & $\begin{array}{c}\text { Rescue } \\
\text { Analgesia } \\
\text { (Number) }\end{array}$ \\
GROUP & $377.29+131.061$ & $230.94+90.01$ & 10 \\
BM & $326.15+116.303$ & $228.10+97.182$ & 11 \\
\hline
\end{tabular}


Level of block achieved after $20 \mathrm{~min}$.

\begin{tabular}{|c|c|c|}
\hline Sensory Level & Group BF (\%) & Group BM (\%) \\
T4 & $1(3.5)$ & $1(3.4)$ \\
T6 & $2(6.6)$ & $0(0.0)$ \\
T8 & $5(6.8)$ & $4(13.3)$ \\
T9 & $2(64.4)$ & $2(6.8)$ \\
T10 & $19(3.5)$ & $14(45.8)$ \\
T11 & $1(3.2)$ & $7(24.3)$ \\
T12 & $0(0)$ & $2(6.8)$ \\
TOTAL & $\mathbf{3 0}$ & $\mathbf{3 0}$ \\
\hline
\end{tabular}

\section{DISCUSSION}

This study had demonstrated increase in duration of sensory blockade and postoperative analgesia after giving intrathecal injection of magnesium and fentanyl to hyperbaric $0.5 \%$ bupivacaine in patients undergoing infraumbilical surgery. The effect of analgesia with magnesium was comparable to fentanyl. None of the patients had somnolence or pruritus in these groups.

Earlier studies demonstrated dose dependent effect of intrathecal magnesium on postoperative analgesia. Bupivacaine provided analgesia for approximately $2 \mathrm{~h}$. and 4 h. $30 \mathrm{~min}$. respectively. Khezri et al.(3) also demonstrated delayed onset of analgesia. Also, metabolism of bupivacaine increasing due to activation of p450 cytochrome by magnesium sulphate may be responsible for the delayed onset of spinal anaesthesia.(4) This may be the reason for lesser duration of analgesia compared to fentanyl as reported in other studies. Unlugenc et al. in their study on intrathecal magnesium sulphate showed that it does not affect the onset or maximal level of sensory blockade, implying that it has an effect solely at the spinal level.(5)

In our study, maximum number of patients achieved the block up to T10 level. With magnesium, in Group BM there was slower ascent of the drug, probably due to change in baricity of the drug. With $100 \mathrm{mg}$ of intrathecal magnesium (Group BM), we observed increased duration of analgesia (331.12 min.) without increase in adverse effects as observed with adjuvant fentanyl (BF) group. This prolongation of analgesia is consistent with the experimental synergistic interaction between spinal local anaesthetic and NMDA antagonists like magnesium, which causes antinociceptive effects via different mechanisms, hence the rationale for combining the two.(5) Group BM patients had a reduced total consumption of opioids in the first $24 \mathrm{~h}$. after surgery. Taken together, these results indicate that in order for total analgesic requirement to be reduced with magnesium sulphate are required, similar to the dose used in the study by Arcioni et al.(6) Dayioglu et al.

Although $100 \mathrm{mg}$ magnesium sulphate reduced the post-operative analgesic requirement; this study was $100 \mathrm{mg}$ magnesium sulphate could replace fentanyl, thereby avoiding opioid side effects such as sedation, pruritus and respiratory depression. Analysis of intra-operative haemodynamics showed that the incidence of hypotension and bradycardia was more in fentanyl group as compared to magnesium group. The intrathecal dose of $100 \mathrm{mg}$ magnesium sulphate that we used was comparable to that of the study by Arcioni et al. and Khalili et al.(6) and Khalili et al.(7)

He found that $100 \mathrm{mg}$ magnesium sulphate decreased the post-operative analgesic requirement and without inducing adverse reactions. Though IV magnesium is known to cause hypotension when used to treat eclampsia.[8] We found no significant haemodynamic effect following the magnesium to our spinal solution. The clinical trials performed to date have not reported any evidence of neurological sequel or other deleterious effects in humans.(9),(10),(11) None of our patients had pruritus. None of the patients had somnolence $>2$ points in any group.

\section{CONCLUSION}

In conclusion, magnesium sulphate at $100 \mathrm{mg}$ dose or fentanyl $25 \mu \mathrm{g}$ as adjuvants to intrathecal bupivacaine significantly prolongs the duration of the both sensory block and analgesia, but fentanyl $25 \mu \mathrm{g}$ with $15 \mathrm{mg}$ bupivacaine (Group BF) in all haemodynamic parameters are decreased by more than $20 \%$ and the magnesium sulphate with bupivacaine (Heavy 0.5\%) (Group BM) provides a better haemodynamic stability than fentanyl (Group BF) and with less side effects.

\section{REFERENCES}

1. Ko SH, Lim HR, Kim DC, et al. Magnesium sulfate does not reduce postoperative analgesic requirements. Anesthesiology 2001;95(3):640-6.

2. Nath MP, Garg R, Talukdar T, et al. To evaluate the efficacy of intrathecal magnesium sulphate for hysterectomy under subarachnoid block with bupivacaine and fentanyl: a prospective randomized double blind clinical trial. Saudi J Anaesth 2012;6(3):254-8.

3. Khezri MB, Yaghobi S, Hajikhani M, et al. Comparison of postoperative analgesic effect of intrathecal magnesium and fentanyl added to bupivacaine in patients undergoing lower limb orthopedic surgery. Acta Anaesthesiol Taiwan 2012;50(1):19-24.

4. Morrison AP, Hunter JM, Halpern SH, et al. Effect of intrathecal magnesium in the presence or absence of local anaesthetic with and without lipophilic opioids: a systematic review and meta-analysis. $\mathrm{Br} \mathrm{J}$ Anaesth 2013;110(5):702-12.

5. Unlugenc $\mathrm{H}$, Ozalevli M, Gunduz M, et al. Comparison of intrathecal magnesium, fentanyl, or placebo combined with bupivacaine $0.5 \%$ for parturients undergoing elective cesarean delivery. Acta Anaesthesiol Scand 2009;53(3):346-53.

6. Arcioni R, Palmisani S, Tigano S, et al. Combined intrathecal and epidural magnesium sulfate supplementation of spinal anesthesia to reduce postoperative analgesic requirements: a prospective, randomized, double-blind, controlled trial in patients undergoing major orthopedic surgery. Acta Anaesthesiol Scand 2007;51(4):482-9.

7. Khalili G, Janghorbani M, Sajedi P, et al. Effects of adjunct intrathecal magnesium sulfate to bupivacaine for spinal anesthesia: a randomized, double-blind trial in patients undergoing lower extremity surgery. J Anesth 2011;25(6):892-7.

8. Jeffrey Michael Smith, Richard F Lowe, Judith Fullerton, et al. An integrative review of the side effects related to the use of magnesium sulfate for pre-eclampsia and eclampsia management. BMC Pregnancy Childbirth 2013;13:34. 
9. Pascual-Ramírez J, Gil-Trujillo S, Alcantarilla C. Intrathecal magnesium as analgesic adjuvant for spinal anesthesia: a meta-analysis of randomized trials. Minerva Anestesiol 2013;79(6):667-78.

10. Saeki H, Matsumoto M, Kaneko S, et al. Is intrathecal magnesium sulfate safe and protective against ischemic spinal cord injury in rabbits? Anesth Analg 2004;99(6):1805-12.
11. Ozdogan L, Sastim H, Ornek D, et al. Neurotoxic effects of intrathecal magnesium sulphate. Braz J Anesthesiol 2013;63(1):139-43. 